\title{
Pemberdayaan Masyarakat Melalui Pelatihan Ergo-Entrepreneurship Untuk Meningkatkan Kualitas Hidup dan Sikap Kewirausahaan Karyawan Pembuat Pempek PT Cita Rasa Palembang
}

\author{
Rinamurti $^{1}$ dan Heri Setiawan ${ }^{2}$ \\ Prodi Manajemen, Fakultas Bisnis dan Akuntansi ${ }^{1}$ \\ Prodi Teknik Industri, Fakultas Sains dan Teknologi ${ }^{2}$ \\ Universitas Katolik Musi Charitas \\ Email: rinamurti@ukmc.ac.id
}

\begin{abstract}
ABSTRAK
Tujuan utama penelitian adalah mengetahui pemberdayaan masyarakat melalui pelatihan ergoentrepreneurship dapat meningkatkan kualitas hidup yang dinilai dari penurunan keluhan muskuloskeletal, kelelahan dan beban kerja karyawan pembuat Pempek Belida PT Cita Rasa Palembang, dan meningkatkan sikap kewirausahaannya. Penelitian eksperimental ini menggunakan rancangan pre and posttest group design (treatment by subjects design) dan melibatkan 30 orang sampel yang dipilih secara acak bertingkat (multistage random sampling).Variabel bebasnya adalah implementasi hasil pelatihan pemberdayaan masyarakat berupa pelatihan ergo-entrepreneurship. Variabel tergantungnya adalah (1) kualitas hidup yang dinilai dari indikator keluhan muskuloskeletal, kelelahan, dan beban kerja serta (2) sikap kewirausahaan karyawan pembuat Pempek Belida PT Cita Rasa Palembang. Data yang diperoleh antara sebelum dan sesudah implementasi hasil pelatihan ergo-entrepreneurship akan dianalisis dengan uji $t$ paired pada taraf signifikansi 5\% $(\alpha=0,05)$. Hasil penelitian pemberdayaan karyawan pembuat Pempek Belida PT Cita Rasa Palembang melalui pelatihan ergo-entrepreneurship yang meningkatkan prosentase kualitas hidup secara bermakna $(p<0,05)$ dilihat dari: penurunan keluhan muskuloskeletal sebesar $25,02 \%$; penurunan kelelahan karyawan sebesar $20,20 \%$; dan penurunan beban kerja sebesar $21,30 \%$; dan meningkatkan prosentase sikap kewirausahaan karyawan sebesar 31,42\%.
\end{abstract}

Kata kunci: ergo-entrepreneurship, kualitas hidup, pemberdayaan, sikap kewirausahaan

\begin{abstract}
The main objective of this research is to find out that community empowerment through ergoentrepreneurship training can improve the quality of life as assessed by decreasing musculoskeletal complaints, fatigue and workload of employees who make Pempek Belida PT Cita Rasa Palembang, increase productivity seen from the aspect of the number of sales of Pempek Belida and increase entrepreneurial attitude. This experimental study used a pre and posttest group design (treatment by subjects design) and involved 30 samples who were randomly selected stratified (multistage random sampling). The independent variable was the implementation of the results of community empowerment training in the form of ergoentrepreneurship training. The dependent variables are (1) quality of life as assessed from indicators of musculoskeletal complaints, fatigue, and workload, and (2) entrepreneurial attitudes of employees who make Pempek Belida PT Cita Rasa Palembang. The data obtained between before and after the implementation of the results of ergo-entrepreneurship training will be analyzed using paired t test at a significance level of 5\% $(\alpha=0.05)$. The results of the research on the empowerment of employees who made Pempek Belida PT Cita Rasa Palembang through ergo-entrepreneurship training which: increased the percentage of quality of life significantly ( $p<0.05$ ) seen from: decreased musculoskeletal complaints by $25.02 \%$; decrease employee fatigue by 20.20\%; and decrease in workload by 21.30\%; and increasing the percentage of employee entrepreneurial attitudes by $31.42 \%$.
\end{abstract}

Keywords: ergo-entrepreneurship, quality of life, empowerment, pemberdayaan, and entrepreneurial attitudes 


\section{PENDAHULUAN}

Habit dalam mendesain stasiun dan proses kerja, sampai saat ini belum mengacu kepada data antropometri pekerja yang ada di areal tempat pekerja beraktivitas. Umumnya yang digunakan sebagai acuan adalah data sekunder yang ada pada literatur, sumber bacaan yang relevan yang umumnya masih menggunakan ukuran orang barat atau kebiasaan dan budaya setempat. Untuk mengatasi masalah tersebut perlu dilakukan eksplorasi data dasar yang akan digunakan sebagai acuan di dalam membuat desain tempat kerja yang ergonomis. Melalui pendekatan sistemik, holistik, interdisipliner dan partisipatori (SHIP Approach) akan terwujud desain tempat kerja dan proses kerja yang secara teknis sesuai dengan pekerjanya dan secara fisiologis tidak menimbulkan keluhan muskuloskeletal, tidak mengakibatkan beban kerja yang terlalu berat dan dapat memperlambat munculnya kelelahan serta meningkatkan kepuasan kerja (Manuaba, 2015; Bahri, et al, 2013; Tanjung, 2015; Mokaya, et al, 2013, Setiawan, 2020). Antropometri merupakan ukuran dan proporsi dimensi tubuh manusia yang mempunyai manfaat praktis untuk menentukan ukuran tempat duduk, meja kerja, jangkauan, genggaman, ruang gerak dan batas-batas gerakan sendi (Grandjean, 2007). Jika dikaji mengenai hubungan antara alat, menusia, dan pekerjaannya masing-masing, maka data antropometri akan sangat dibutuhkan untuk memperoleh kesesuaian antara ukuran diri pekerja dengan alat-alat yang digunakan. Saat ini masih belum banyak dimanfaatkan ukuran-ukuran antropometri di dalam mendesain alat-alat kerja dan tempat kerja. Kebiasaan ini merupakan kearifan lokal yang dapat diterapkan di masyarakat dengan mengacu kepada prinsip-prinsip ergonomi.

Penerapan ergonomi yang mengupayakan agar pekerja selalu dalam kondisi sehat, aman, dan nyaman, serta terbebas dari kondisi stres dalam proses kerja merupakan suatu yang urgen untuk dilaksanakan dan sesegera mungkin harus diimplementasikan (Manuaba, 2015; Hsieh, 2013; Marchelia, 2014: Setiawan, 2012). Jika hal ini diabaikan, maka kualitas hidup pekerja diyakini akan terganggu bahkan bisa menimbulkan deformitas pada organ tubuhnya dan pada akhirnya akan menurunkan produktivitas kerja. Salah satu cara yang bisa ditempuh agar para pekerja yang berkecimpung di dalam kegiatan yang ada di industri kecil tetap dalam kondisi yang ENASE (Efektif, Nyaman, Aman, Sehat, dan Efisien) menghasilkan produktivitas yang optimal serta memiliki sikap kewirausahaan yang memadai maka diperlukan kaidah-kaidah ergonomi yang bersinergi dengan kewirausahaan atau disebut dengan istilah ergo-entrepreneurship. Seandainya hal ini tidak dilakukan maka akan berdampak pada kualitas hidup dengan menimbulkan berbagai macam 
gangguan, kelainan dan penyakit yang terkait dengan sistem otot dan rangka, misalnya; (1) terganggunya mekanika tubuh manusia secara umum, (2) bisa terjadi luka atau cedera pada persendian, (3) epimisium dan perimisium otot bisa sobek, (4) rasa sakit pada vertebrae (tulang belakang) dan (5) terjadi deformitas atau degenerasi pada diskus intervertebralis (cakram atau piringan pada persendian tulang belakang) (Grandjean, 2007; Bahri, et al, 2013). Dengan demikian kualitas hiudp pekerja akan terancam yang pada akhirnya produktivitas kerja akan menurun dan berimplikasi kepada mekanisme pemasaran produk. Berdasarkan latar belakang masalah tersebut dapat dibuat rumusan masalah penelitian sebagai berikut. "Bagaimanakah strategi pemberdayaan masyarakat melalui pelatihan ergo-entrepreneurship dapat meningkatkan kualitas hidup yang dinilai dari penurunan keluhan muskuloskeletal, penurunan kelelahan, penurunan beban kerja, peningkatan produktivitas jika dilihat dari aspek jumlah penjualan Pempek Belida dan peningktan sikap kewirausahaan PT Cita Rasa Palembang?”.

\section{METODE}

Penelitian eksperimental dengan rancangan pre and post test group design (treatment by subjects design), ini dirancang berdasarkan pendekatan ergonomic partisipatory. Partisipatori artinya semua orang yang terlibat dalam pemecahan masalah tersebut harus dilibatkan sejak awal secara maksimal agar dapat diwujudkan mekanisme kerja yang kondusif dan diperoleh produk yang berkualitas sesuai dengan tuntutan jaman (Manuaba, 2015). Selanjutnya, dilakukan eksplorasi data kondisi kerja karyawan pembuat Pempek Belida yang menyertai PT Cita Rasa Palembang selama bekerja dan digunakan untuk menyusun strategi pemberdayaan masyarakat yang mengacu konsep ergoentrepreneurship. Pengembangan strategi tersebut diarahkan kepada implementasi dari sinergitas konsep-konsep ergonomi dan kewirausahaan serta dampaknya terhadap kualitas hidup, produktivitas dan sikap kewirausahaan.

Pola dasar penelitian eksperimental dengan rancangan pre and post test group design (treatment by subjects design), sebagai berikut (Colton, 2007).

$$
\text { P ---- RS-------O1-----(-)----O2------WOP-----O3------(p)-------04 }
$$

Gambar 1. Bagan Rancangan Penelitian

\section{Keterangan:}

$\mathrm{P}=$ populasi karyawan pembuat Pempek Belida PT Cita Rasa Palembang; RS = sampel dipilih secara random; $\mathrm{O} 1=$ pendataan sebelum kerja (periode $\mathrm{I}) ; \mathrm{O} 2=$ pendataan sesudah kerja (periode $\mathrm{I}) ; \quad \mathrm{O} 3=$ pendataan sebelum kerja (periode II); O4 = pendataan sesudah kerja (periode II); $(-)=$ kondisi kerja 
sebelum perlakuan $($ Periode I); $(\mathrm{p})=$ kondisi kerja setelah perlakuan $($ Periode II); dan WOP = washing out period selama dua hari.

Subjek penelitian adalah karyawan pembuat Pempek Belida PT Cita Rasa Palembang yang sekaligus simpatisan penjual/resller pempek yang diproduksi oleh PT Cita Rasa Palembang, Provinsi Sumatera Selatan. Populasi target adalah semua karyawan PT Cita Rasa Palembang dan simpatisan reseller. Populasi terjangkau adalah semua PT Cita Rasa Palembang yang memenuhi kriteria inklusi yang berjumlah 30 orang sampel karyawan pembuat Pempek Belida dan simpatisan reseller PT Cita Rasa Palembang dengan sampel yang terpilih dalam penentuan jumlah sampel dan dilibatkan secara penuh pada penelitian ini. Variabel bebasnya adalah implementasi hasil pelatihan pemberdayaan masyarakat berupa pelatihan ergo-entrepreneurship. Variabel tergantungnya adalah (1) kualitas hidup perspektif kesehatan karyawan yang dinilai dari indikator keluhan muskuloskeletal, kelelahan, dan beban kerja, dan (2) sikap kewirausahaan karyawan pembuat Pempek Belida PT Cita Rasa Palembang. Variabel kontrolnya adalah kondisi subjek (umur, tinggi badan, berat badan, dan pengalaman kerja), antropometri PT Cita Rasa Palembang, dan kondisi lingkungan di tempat kerja (suhu basah, suhu kering, kelembaban relatif, dan intensitas cahaya).

Data yang diperoleh antara sebelum dan sesudah implementasi hasil pelatihan ergo-entrepreneurship dianalisis sebagai berikut: Uji deskriptif terhadap (1) data kualitas hidup karyawan pembuat Pempek Belida PT Cita Rasa Palembang yang dilihat dari indikator keluhan muskuloskeletal, kelelahan, dan beban kerja, (2) produktivitas yang dilihat dari jumlah penjualan Pempek Belida, (3) data sikap kewirausahaan, (4) kondisi subjek, dan (5) kondisi lingkungan fisik kerja dengan mencari rerata dan simpang bakunya, serta (6) antropometri karyawan pembuat Pempek Belida PT Cita Rasa Palembang dengan mencari persentil 5, 50, dan 95. Uji normalitas data terhadap (1) data kualitas hidup PT Cita Rasa Palembang yang dilihat dari indikator keluhan muskuloskeletal, kelelahan, dan beban kerja, (2) data produktivitas yang dilihat dari jumlah penjualan Pempek Belida, dan (3) data sikap kewirausahaan dengan uji Kolmogorov-Smirnov pada taraf signifikansi 5\% $(\alpha=0,05)$, dan Uji hipotesis terhadap (1) kualitas hidup karyawan PT Cita Rasa Palembang yang dilihat dari indikator keluhan muskuloskeletal, kelelahan, dan beban kerja, dan (2) sikap kewirausahaan dengan uji $t$ paired ( $t$ independent samples) pada taraf signifikansi 5\% $(\alpha=0,05)$. 


\section{HASIL, PEMBAHASAN DAN DAMPAK}

Temuan pada penelitian ini menunjukkan bahwa kondisi subjek dilihat dari rerata umur mennunjukkan bahwa subjek dalam kategori umur produktif, karena diperoleh rerata umur 27,51 tahun. Tinggi badan subjek dalam kategori ideal jika dibandingkan dengan berat badannya berdasarkan perhitungan tinggi badan 167,91 cm dikurangi dengan 100 menjadi 67,9 dan selanjutnya dikurangi dengan 10\%-nya (6,791). Selanjutnya, 67,91 dikurangi dengan 6,791 sehingga menjadi 61,119. Pada penelitian ini ditemukan bahwa berat badan subjek $62,00 \mathrm{~kg}$, sehingga dinyatakan dalam kategori ideal. Rerata pengalaman kerja Karyawan Pembuat Pempek Belida PT Cita Rasa Palembang selama 27,51 tahun menunjukkan bahwa mereka sudah sangat teradaptasi dengan kondisi kerja yang menyertainya selama 8 (delapan) jam kerja per hari. Melihat kondisi subjek yang sedemikian rupa menunjukkan bahwa kondisi subjek dapat dikontrol dengan baik sehingga diyakini bahwa kondisi subjek tidak menimbulkan efek tersembunyi (masking effect) pada penelitian ini. Apalagi dengan menggunakan rancangan treatment by subject (rancangan sama subjek) tampaknya efek tersembunyi tersebut akan semakin diminimalkan. Itu berarti bahwa perubahan kualitas kesehatan yang dinilai berdasarkan indikator keluhan muskuloskeletal, kelelahan, dan beban kerja serta sikap kewirausahaan Karyawan Pembuat Pempek Belida PT Cita Rasa Palembang semata-mata diakibatkan oleh perlakuan yang diberikan berupa perbaikan kondisi kerja sebagai implementasi dari hasil pelatihan ergoentrepreneurship. Dalam hal ini Manuaba (2003) dalam Setiawan (2017) menyatakan bahwa kemampuan manusia sangat ditentukan oleh faktor-faktor profil, kapasitas fisiologis, kapasitas psikologis dan kapasitas biomekanik. Sedangkan tuntutan tugas dipengaruhi oleh karakteristik dari materi pekerjaan, tugas yang harus dilakukan, organisasi dan lingkungan dimana pekerjaan itu dilakukan.

Ukuran dimensi tubuh atau antropometri Karyawan Pembuat Pempek Belida PT Cita Rasa Palembang yang digunakan sebagai acuan di dalam mendesain tempat kerja yang dianalisis pada persentil 5, 50, dan 95. Terkait dengan temuan tersebut Sutajaya (2018) menyatakan bahwa di dalam mendesain alat kerja dan ruang kerja yang mengacu kepada antropometri pengguna, perlu dipertimbangkan: (a) tinggi rendahnya tuntutan terhadap beban otot pada saat beraktivitas, (b) tingkat bahaya yang ditimbulkan pada saat melakukan aktivitas dengan menggunakan alat kerja tertentu dan di ruang kerja tertentu pula, (c) letak beban paling besar pada saat mengangkat dan mengangkut beban, mengoperasikan alat-alat kerja, duduk di kursi kerja, bekerja di meja kerja dan lain-lain, (d) posisi kerja pada saat melakukan kegiatan (duduk, berdiri, jongkok, setengah jongkok, 
duduk bersila, kombinasi), (e) sikap kerjanya (alamiah atau tidak alamiah), (f) sifat kerjanya statis atau dinamis dilihat dari kontraksi otot yang terjadi pada saat melakukan aktivitas, (g) kemungkinan variasi posisi dan sikap kerja, (h) pola-pola gerakan badan yang dikaitkan dengan batasan-batasan gerakan sendi, (i) lamanya kerja dengan memanfaatkan tenaga fisik atau otot, (j) tinggi rendahnya presisi atau ketelitian yang diinginkan, dan (k) organ-organ yang terlibat langsung dengan komponen-komponen alat.

Kondisi lingkungan yang dianalisis antara sebelum dan sesudah implementasi hasil pelatihan ergo-entrepreneurship menunjukkan bahwa kondisinya komparabel yang ditunjukkan dengan nilai $\mathrm{p}>0,05$ pada setiap indikator terukur pada kondisi lingkungan kerja dengan rincian; (a) rerata suhu basah adalah $27,89^{\circ} \mathrm{C}$ sebelum implementasi hasil pelatihan ergo-entrepreneurship dan $27,00^{\circ} \mathrm{C}$ sesudah implementasi hasil pelatihan ergoentrepreneurship dengan nilai $\mathrm{t}=0,347$ dan nilai $\mathrm{p}=0,733$, (b) rerata suhu kering adalah $30,33^{\circ} \mathrm{C}$ sebelum implementasi hasil pelatihan ergo-entrepreneurship dan $30,44^{\circ} \mathrm{C}$ sesudah implementasi hasil pelatihan ergo-entrepreneurship dengan nilai $t=0,329$ dan nilai $p=$ 0,747, (c) rerata kelembaban relatif adalah 77,00\% sebelum implementasi hasil pelatihan ergo-entrepreneurship dan $77,22 \%$ sesudah implementasi hasil pelatihan ergoentrepreneurship dengan nilai $\mathrm{t}=0,263$ dan nilai $\mathrm{p}=0,796$, dan $(\mathrm{d})$ intensitas cahaya adalah 288,89 lux sebelum implementasi hasil pelatihan ergo-entrepreneurship dan 272,22 lux sesudah implementasi hasil pelatihan ergo-entrepreneurship dengan nilai $\mathrm{t}=0,905$ dan nilai $\mathrm{p}=0,379$. Ini menunjukkan bahwa suhu basah, suhu kering, kelembaban relatif, dan intensitas pencahayaan sebagai indikator kondisi lingkungan di tempat kerja adalah sama antara sebelum dan sesudah implementasi hasil pelatihan ergo-entrepreneurship. Terkait dengan temuan tersebut Manuaba (2015) menyatakan bahwa suhu udara yang nyaman untuk orang Indonesia adalah antara 22 s.d. $28^{\circ} \mathrm{C}$, dan kelembaban relatifnya adalah antara 70 s.d. $80 \%$. Grandjean (2007) menyatakan bahwa intensitas cahaya yang memadai di tempat kerja adalah minimal 200 lux. Sutajaya (2018) menyatakan bahwa pencahayaan yang baik sangat penting, agar pekerjaan dapat dilakukan dengan benar dan dalam situasi nyaman dan pada saat melakukan aktivitas dapat melihat objek dengan jelas dan cepat, sehingga tidak melelahkan otot-otot mata. Itu berarti bahwa kondisi lingkungan yang menyertai para Karyawan Pembuat Pempek Belida PT Cita Rasa Palembang selama bekerja adalah dalam kondisi nyaman atau sesuai dengan aklimatisasi orang Indonesia. 


\section{a) Keluhan Muskuloskeletal Karyawan Pembuat Pempek Belida PT Cita Rasa Palembang}

Keluhan muskuloskeletal Karyawan Pembuat Pempek Belida PT Cita Rasa Palembang antara sebelum dan sesudah perbaikan kondisi kerja yang merupakan implementasi dari hasil pelatihan ergo-entrepreneurship menurun secara bermakna sebesar 5,67\% jika dilihat dari keluhan muskuloskeletal sesudah kerja dan terjadi penurunan sebesar 25,02\% $(\mathrm{p}<0,05)$ jika dilihat dari selisih antara keluan muskuloskeletal sebelum dan sesudah kerja. Ini menunjukkan bahwa perbaikan kondisi kerja berupa penyesuaian antropometri dengan alat kerja dan ruang kerja, pemberian istirahat pendek, pengaturan gizi kerja, dan penerapan istirahat aktif yang dilakukan secara kombinatif dapat mengurangi keluhan muskuloskeletal Karyawan Pembuat Pempek Belida PT Cita Rasa Palembang. Itu terjadi sebagai akibat dari perubahan kontraksi isometrik (statis) menjadi isotonik (dinamis) yang dapat dilakukan melalui perubahan-perubahan kondisi kerja tersebut. Berkaitan dengan temuan tersebut, Setiawan (2019a) menyatakan bahwa perbaikan kondisi kerja sehingga menjadi ergonomis memang sangat diperlukan agar pekerja terhindar dari keluhan otot, sebagai akibat dari alih teknologi yang kurang tepat. Dalam hal ini sikap kerja yang tidak alamiah dapat bertindak sebagai penyebab timbulnya berbagai keluhan pada sistem otot rangka. Untuk mengatasi masalah tersebut perlu diimplementasi konsep-konsep ergonomi yang dikaji di dalam materi pelatihan ergoentrepreneurship yang berkaitan dengan kriteria sikap tubuh yang ideal dalam melakukan suatu kegiatan atau pekerjaan. Kriteria tersebut adalah: (a) otot yang bekerja secara statis sangat sedikit, (b) dalam melakukan tugas dengan memakai tangan dilakukan secara mudah dan alamiah, (c) muscular effort yang relatif kecil dapat dipertahankan, (d) sikap kerja yang berubah-ubah atau dinamis lebih baik daripada sikap kerja statis rileks, (e) sikap kerja statis rileks lebih baik daripada sikap kerja statis tegang. Temuan tersebut juga sesuai dengan pendapat Pheasant (1991) dalam Setiawan (2019b) yang menyatakan bahwa perbaikan kondisi kerja dalam mengatasi sikap tubuh selama bekerja hendaknya mengacu kepada prinsip: (a) cegah inklinasi ke depan pada leher dan kepala, (b) cegah inklinasi ke depan pada tubuh, (c) cegah penggunaan anggota gerak bagian atas dalam keadaan terangkat, (d) cegah pemutaran badan dalam sikap asimetris (terpilin), (e) persendian hendaknya dalam rentangan sepertiga dari gerakan maksimum, (f) sediakan sandaran punggung dan pinggang pada semua tempat duduk, dan (g) jika menggunakan tenaga otot, hendaknya dalam posisi yang mengakibatkan kekuatan maksimum. Setiawan (2012) 
melaporkan redesain stasiun kerja blanket basah menurunkan kelelahan pekerja sebesar $18,84 \%$.

\section{b) Kelelahan Karyawan Pembuat Pempek Belida PT Cita Rasa Palembang sebagai Indikator Kualitas Hidup}

Temuan pada penelitian ini adalah terjadi penurunan kelelahan antara sebelum dan sesudah perbaikan kondisi kerja yang merupakan implementasi dari hasil pelatihan ergoentrepreneurship. Dalam penelitian ini ditemukan bahwa kelelahan sesudah kerja menurun secara bermakna sebesar $6,78 \%$ dan dilihat dari selisih antara kelelahan sebelum dan sesudah kerja ternyata terjadi penurunan secara bermakna sebesar 20,20\% ( $<<0,05)$. Itu terjadi sebagai akibat dari adanya perbaikan kondisi kerja berupa pemberian istirahat pendek, pengaturan gizi kerja, dan penerapan istirahat aktif. Dinyatakan demikian karena dalam pemberian istirahat pendek dimungkinkan untuk dilakukan pembayaran utang oksigen, istirahat aktif dapat mengubah kondisi statis menjadi dinamis, dan pengaturan gizi kerja dapat mengatasi kekurangan glukosa pada saat melakukan aktivitas kerja. Itu berarti bahwa perbaikan kondisi kerja yang merupakan implementasi dari hasil pelatihan ergoentrepreneurship ternyata dapat meningkatkan kualitas kesehatan Karyawan Pembuat Pempek Belida PT Cita Rasa Palembang dilihat dari penurunan kelelahan Karyawan Pembuat Pempek Belida PT Cita Rasa Palembang. Diyakini demikian karena beberapa peneliti lain melaporkan bahwa perbaikan kondisi kerja dengan mengimplementasikan ergonomi dapat mengurangi kelelahan. Penelitian yang bersinergi dengan temuan pada penelitian ini adalah: (a) Purnomo (2007) melaporkan bahwa pekerja di industri kecil pembuat gerabah di Kasongan Bantul mengalami penurunan kelelahan sebesar 77,50\% $(\mathrm{p}<0,05)$ setelah diterapkan sistem kerja dengan pendekatan ergonomi total; (b) Widana, dkk (2012) melaporkan bahwa kelelahan petani sayur menurun sebesar 13,06\% setelah dilakukan implementasi ergonomi pada pengolahan tanah pertanian di Tabanan Bali; (c) Handari (2013) melaporkan bahwa penerapan ergo-psikofisiologi dapat mengurangi kelelahan karyawan akuntansi sebesar 22,18\%; (d) Adnyana (2013) melaporkan bahwa aplikasi sinergi Ergo-Mechanical-System dapat mengurangi kelelahan pekerja wanita pembuat sarana banten sebesar 22,23\%; dan (e) Setiawan (2012) melaporkan redesain stasiun kerja blanket basah menurunkan kelelahan pekerja sebesar 18,84\%. 


\section{c) Beban Kerja Karyawan Pembuat Pempek Belida PT Cita Rasa Palembang sebagai Indikator Kualitas Hidup}

Terjadi penurunan beban kerja antara sebelum dan sesudah perbaikan kondisi kerja yang merupakan implementasi dari hasil pelatihan ergo-entrepreneurship. Dalam penelitian ini ditemukan bahwa beban kerja sesudah kerja yang dinilai berdasarkan denyut nadi kerja ternyata menurun secara bermakna sebesar 7,48\% dan dilihat dari selisih antara denyut nadi istirahat dan denyut nadi kerja yang diistilahkan dengan nadi kerja ternyata terjadi penurunan secara bermakna sebesar 21,30\% ( $<<0,05)$. Itu terjadi sebagai akibat dari adanya perbaikan kondisi kerja berupa pemberian istirahat pendek, pengaturan gizi kerja, dan penerapan istirahat aktif. Dinyatakan demikian karena perbaikan kondisi kerja tersebut terutama istirahat aktif dan istirahat pendek memberikan kesempatan kepada sistem kardiovaskular untuk kembali bekerja secara normal setelah sebelumnya dipacu untuk pemenuhan energi ketika dilakukan aktivitas yang cukup berat dan sirkulasi darah dapat berjalan lancar yang ditandai dengan semakin menurunnya frekuensi denyut nadi. Temuan tersebut sesuai dengan pendapat Sutajaya (2018) yang menyatakan bahwa beban kerja dipengaruhi oleh faktor eksternal yaitu faktor-faktor yang berasal dari luar tubuh. Beban kerja eksternal dipengaruhi oleh: (a) task yang bersifat fisik seperti: stasiun kerja, sikap kerja, frekuensi kerja, kerja otot dan lain-lain dan yang bersifat kerja mental seperti: kompleksitas pekerjaan, tuntutan dari pekerjaan, tanggung-jawab terhadap pekerjaan, beban moral dan lain-lain dan (b) organisasi yaitu menyangkut tentang pengaturan waktu kerja dan istirahat, sistem pengupahan, sistem kerja, tim kerja, dan kerja bergilir. Temuan tersebut sesuai dengan pendapat Setiawan (2013) yang menyatakan bahwa redesain stasiun kerja blanket basah di PT Sunan Rubber menurunkan beban kerja pekerja sebesar 24,39\%.

\section{d). Sikap Kewirausahaan Karyawan Pembuat Pempek Belida PT Cita Rasa Palembang}

Temuan pada penelitian ini adalah terjadi peningkatan sikap kewirausahaan antara sebelum dan sesudah perbaikan kondisi kerja yang merupakan implementasi dari hasil pelatihan ergo-entrepreneurship. Dalam penelitian ini ditemukan bahwa sikap kewirausahaan meningkat secara bermakna sebesar 31,42\% ( $<<0,05)$. Itu terjadi sebagai akibat dari adanya kajian kewirausahaan yang dilakukan selama proses pelatihan. Pada kegiatan pelatihan tersebut, peningkatan pengetahuan subjek tentang kewirausahaan selalu menjadi target pelatihan. Harapannya adalah melalui peningkatan pengetahuan akan berkontribusi terhadap peningkatan sikap kewirausahaan. Dinyatakan demikian karena 
pada pelatihan tersebut subjek selalu dimotivasi agar bisa aktif dan kreatif di dalam memasarkan produknya baik melalui jasa penjual maupun melalui media elektronik. Temuan tersebut sesuai dengan pendapat Sutajaya (2018) yang menyatakan bahwa orangorang yang memiliki kreativitas dan inovasi yang tinggi dalam hidupnya akan selalu berusaha untuk berpikir kreatif dan berperilaku inovatif yang dijadikan dasar, sumber daya, tenaga penggerak, tujuan, siasat dan kiat dalam menghadapi tantangan hidup. Seorang wirausahawan tidak hanya dapat berencana, berkata-kata tetapi juga berbuat, merealisasikan rencana-rencana dalam pikirannya ke dalam suatu tindakan yang berorientasi pada kesuksesan. Dalam hal ini dibutuhkan kreativitas yang tinggi dan pola pikir tentang sesuatu yang baru, serta inovasi, sebagai tindakan dalam melakukan sesuatu yang baru.

\section{SIMPULAN}

Bertolak dari hasil analisis dan pembahasan yang dikaji berdasarkan literatur yang relevan dapat disimpulkan pemberdayaan masyarakat melalui pelatihan ergoentrepreneurship karyawan pembuat Pempek Belida PT Cita Rasa Palembang dapat: 1) meningkatkan kualitas hidup perspektif kesehatan dilihat dari; (a) penurunan keluhan muskuloskeletal sebesar 25,02\%, (b) penurunan kelelahan sebesar 20,20\%, (c) penurunan beban kerja sebesar 21,30\%, dan 2) meningkatkan sikap kewirausahaan sebesar 31,42\%.

\section{UCAPAN TERIMA KASIH}

Kami mengucapkan terima kasih yang mendalam kepada jajaran Pimpinan Pabrik Pempek Belida PT Cita Rasa Palembang, Pimpinan Prodi Manajemen Fak. Bisnis dan Akuntansi, Pimpinan Prodi Teknik Industri Fak. Sains dan Teknologi, Universitas Katolik Musi Charitas, dan seluruh pihak yang terlibat dalam PkM ini.

\section{DAFTAR PUSTAKA}

Adnyana, I W.B. 2013. Aplikasi Synergy Ergo-Mechanical System Meningkatkan Kapasitas Kerja Para Pekerja Wanita dan Efisiensi Energi Bahan Bakar Alat Pengering pada Industri Sarana Banten di Blahbatuh Gianyar Bali. Disertasi. Denpasar: Program Pascasarjana Universitas Udayana.

Bahri, Salim, J., Susihono, W. 2013. Perbaikan Postur Kerja dengan Pendekatan Metode RULA dan NIOSH di Bagian Produksi Mixer. Jurnal Teknik Industri, Vol. 1 No. 1, Maret 2013, pp 77-87. ISSN 2302-495X. 
Colton, T. 1985. Statistika Kedokteran. (Terjemahan R. Sanusi). Yogyakarta: Gadjah Mada University Press.

Grandjean, E. 2007. Fitting the task to the Man. A Textbook of Occupational Ergonomis. 4th Edition. London: Taylor \& Francis.

Handari, L.M.I.S. 2013. Ergo-Psikofisiologi Menurunkan Respon Fisiologis Meningkatkan Kesigapan, Kemampuan Kerja dan Work Engagement Karyawan Bagian Akuntansi hotel Bali Hyatt di Denpasar. Disertasi. Program Pascasarjana Universitas Udayana Bali.

Manuaba, A. 2015. Total Ergonomic Approach to Anticipate Multidimensional Development Problems. Ergonomic Seminar 2015. Bali Udayana University.

Mokaya, S.O., Musau, J.L., Wagoki, J., Karanja, K., 2013. Effects of Organizational Work Conditions on Employee Job Satisfaction in The Hotel Industry in Kenya. International Journal of Arts and Commerce Vol.2. No.2. February.

Purnomo, H. 2007. Sistem Kerja dengan Pendekatan Ergonomi Total Mengurangi Keluhan Muskuloskeletal, Kelelahan, dan Beban Kerja serta Meningkatkan Produktivitas Pekerja Industri Gerabah di Kasongan Bantul. Disertasi. Program Pascasarjana Universitas Udayana Bali.

Setiawan, H. 2012. Short Rest Time and Accompanying Work Music Decrease Work Fatigue and Work Stress to Workers at Crumb Rubber Factory. Proceedings International Conference 2012, Southeast Asian Network of Ergonomics Societies Conference (SEANES), Langkawi-Malaysia, July 9-12, 2012. ISBN No. 978-98341742 .

Setiawan, H. 2017. Redesigning the work system of rubber industries based on total ergonomics and ergo-micmac integration. The 2nd International Joint Conference on Science and Technology (IJCST). IOP Publishing. IOP Conf. Series: Journal of Physics: Conf. Series 953 (2017) 012025 doi :10.1088/17426596/953/1/012025.

Setiawan, H. 2019a. Internalization of the champion core values in work system design and ergonomics learning. TICATE 2018. IOP Conf. Series: Materials Science and Engineering 508 (2019) 012088. IOP Publishing doi:10.1088/1757899X/508/1/012088.

Setiawan, H. 2019b. Recommendations of Ergonomic Checkpoints and Total Ergonomics Intervention in The Pempek \& Kemplang Palembang Industry. Proceedings. The 1 st International Conference on Research in Industrial and System Engineering 2019 Proceedings.

Setiawan, H. 2020. Perancangan Alat Bantu Memasukkan Gabah ke dalam Karung yang Ergonomis di Penggilingan Padi Pak Santo. Jurnal Ergonomi Indonesia (The Indonesian Journal of Ergonomic). Vol. 6 No. 1 Hal. 37-44, Juni Tahun 2020 PISSN: 1411-951X, EISSN: 2503-1716.

Setiawan, S. 2013. Desain Stasiun Kerja Blanket Basah Berbasis Ergonomi Meningkatkan Kualitas Hidup dan Produktivitas Pekerja di PT Sunan Rubber 
Palembang Provinsi Sumatera Selatan. Disertasi. Program Pascasarjana Universitas Udayana Bali

Sutajaya, I M. 2018. Ergonomi. Rajawali Pers, PT. Rajagrafindo Persada: Depok.

Tanjung, S. 2015. Analisis Postur Kerja untuk Mengurangi Risiko Muskuloskeletal Disorders Menggunakan Metode Rapid Upper Limb Assessment (RULA). Jurnal Ilmiah Universitas Bakrie. Vol. 3. No. 3. Agustus.

Widana, K. Adiputra, N. Sutjana, I D.P. dan Sutajaya, I M. 2012. Redesign Tractor for Soil Treatment Decreases Productions Cost and Increase Productivity, Health of Workers in Agricultural Industry. Proceeding of the Second International Conference of Southeast Asian Network of Ergonomics Societies. Ed. Halimahtun M. Khalid, Alvin W. Yeo. Martin G. Helander. and Tek Yong Lim. Publisher Damai Sciences ISBN 978-983-41742. 